\title{
Estimasi Periode Ulang Gempa Bumi Di Wilayah Sulawesi Dengan Menggunakan Distribusi Gumbel
}

\author{
Yustiani Frastika1), Guntur Pasau1), Jantje D. Prang2)
}

1) Jurusan Fisika, FMIPA, Unsrat, MANADO

2) Jurusan Matematika, FMIPA, Unsrat, MANADO

\begin{tabular}{l}
\hline K A T A K U N C I \\
\hline Distribusi Gumbel \\
Gempa bumi \\
Periode ulang
\end{tabular}

KEYWOR D S

Gumbel distribution

Earthquake

Return period
AVAILABLE ONLINE

08 November 2013

\begin{abstract}
A B S T R A K
Estimasi periode ulang gempa bumi yang bersifat ekstrim dengan menggunakan Distribusi Gumbel dilakukan untuk menganalisis kejadian gempa bumi yang telah terjadi sebelumnya menggunakan data sejak Januari 1905-Juni 2013. Pengolahan dan analisis data dilakukan dengan dua tahap. Pertama,Pengujian dan pemeriksaan pola sebaran data. Kedua, menentukan periode ulang gempa bumi untuk mengetahui keberulangan gempa ekstrim yang akan terjadi selanjutnya. Hasil analisis yang diperoleh adalah Wilayah Sulawesi sangat rawan terhadap kejadian gempa bumi yang bersifat ekstrim. Tingkat pengulangan kejadian gempa bumi untuk Wilayah Provinsi Sulawesi Utara dalam kurun waktu 62-100 tahun adalah $7 \mathrm{Mw}$, Wilayah Provinsi Gorontalodalam kurun waktu 75-100 tahun adalah 6,8 Mw, Wilayah Provinsi Sulawesi Tengah dalam kurun waktu 82-100 tahun adalah 6,9 Mw, Wilayah Provinsi Sulawesi Selatan dalam kurun waktu 319-686 bulan adalah 6,2 Mw, Wilayah Provinsi Sulawesi Barat dalam kurun waktu 113-217 bulan adalah 6,2 Mw dan Wilayah Provinsi Sulawesi Tenggara dalam kurun waktu 45-97 tahun adalah 6,0 Mw.

A B S T R A C T

The estimation of extreme earthquake return period by using the Gumbel distribution is made to analyze the occurrence of earthquakes that have occurred previously using data from January 1905 to June 2013. Data processing and analysis has been in two stages. First, testing and examination of data distribution patterns to see whether the data follow the theoretical distribution, in this case the Gumbel distribution. Second, determining the return period of the earthquake to see a recurrence of extreme earthquake is going to happen in the future. Results of the analysis showed that Sulawesi Region is highly vulnerable to earthquakes which are extreme. Return period of earthquake on the region of North Sulawesi province in the period of $62-100$ years is $7.0 \mathrm{Mw}$, the region of Gorontalo Province in the period of $75-100$ years is $6.8 \mathrm{Mw}$, the region of Central Sulawesi Province in the period of $82-100$ years is 6.9 Mw, the region of South Sulawesi Province in the period of 319-686 months is $6, .2 \mathrm{Mw}$, the region of West Sulawesi province in the period of 113-217 months is $6.2 \mathrm{Mw}$ and the region of Southeast Sulawesi province in the period of $45-97$ years is $6.0 \mathrm{Mw}$.
\end{abstract}

\footnotetext{
*Corresponding author: Jurusan Fisika FMIPA UNSRAT, Jl. Kampus Unsrat, Manado, Indonesia 95115; Email address: yustianifrastika@yahoo.co.id Published by FMIPA UNSRAT (2013)
} 


\section{Pendahuluan}

Wilayah Indonesia merupakan daerah tektonik aktif yang terletak pada pertemuan tiga lempeng tektonik utama, yaitu lempeng Eurasia di Utara, lempeng Indo-Australia di Selatan dan lempeng Pasifik di Timur serta diantara ke tiga lempeng utama tersebut terdapat lempeng kecil yaitu lempeng Filipina. Dampak positifnya adalah terdapatnya panas bumi, mineral tambang dan gas bumi, panorama yang menarik seperti pegunungan, flora dan fauna baik dipermukaan maupun dibawah laut dan sebagainya. Sedangkan dampak negatif dari keadaan tektonik Indonesia adalah sebagian besar wilayah menjadi rawan terhadap bencana alam, salah satunya adalah gempa bumi (Ibrahim et al., 2010).

Untuk memperkecil dampak negatif dari gempa bumi, diperlukan suatu prediksi periode ulang terjadinya gempa bumi yang bersifat ekstrim. Menurut Sahiu, 2011, Distribusi Gumbel merupakan sebaran yang berhubungan dengan kejadiankejadian ekstrim yang digunakan untuk memprediksi terjadinya gempa bumi, sehingga dapat digunakan untuk melakukan pengkajian tentang masalah ini

Indonesia termasuk Wilayah Sulawesi masuk pada daerah Lingkaran Api. Dapat dilihat pada Gambar 1 berikut ini:

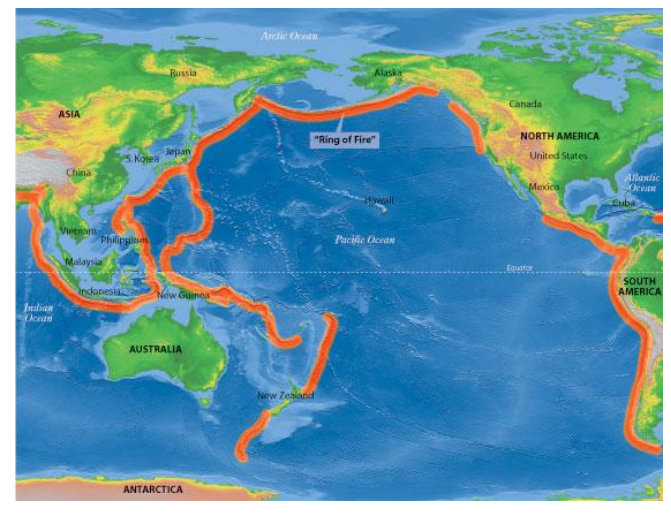

Gambar 1. Lingkaran Api

Kejadian gempa direkam dengan sejumlah instrument yang mempunyai perbedaan metode dalam penentuan ukuran gempa. Skala magnitudo yang digunakan antara lain adalah Magnitudo Permukaan (Surface Magnitude, Ms), Magnitudo Lokal (Local Magnitude, ML), Magnitudo Badan (Body Magnitude, mb) dan Magnitudo Momen (Moment Magnitude, Mw).

Adanya berbagai ukuran skala tersebut maka diperlukan konversi ke dalam skala magnitudo yang sama untuk digunakan dalam analisis kejadian
Pembangkit utama terjadinya gempa bumi adalah pergerakan lempeng tektonik. Akibat pergerakan lempeng, maka di sekitar perbatasan lempeng akan terakumulasi energi dan jika lapisan batuan tidak mampu manahannya maka energi akan terlepas dan menyebabkan terjadinya patahan ataupun deformasi pada lapisan kerak bumi dan terjadilah gempa bumi tektonik. Disamping itu akibat adanya pergerakan lempeng, terjadi patahan/sesar pada lapisan bagian atas kerak bumi yang merupakan pembangkit kedua terjadinya gempa bumi tektonik. Jadi sumber-sumber gempa bumi keberadaannya ada pada perbatasan lempeng-lempeng tektonik dan patahan-patahan aktif. (Ibrahim dan Subardjo, 2005).

Lingkaran Api (Ring of Fire) adalah Daerah yang sering mengalami gempa bumi dan letusan gunung berapi yang mengelilingi cekungan Samudra Pasifik. Daerah ini berbentuk seperti tapal kuda dan mencakup wilayah sepanjang 40.000 km. Daerah ini sering disebut sebagai sabuk gempa Pasifik. Lingkaran Api adalah area dimana terdapat banyak sekali terjadi gempa dan letusan gunung berapi di dalam area Samudera Pasifik (Pratiwi, 2011)

gempa bumi. Konversi Magnitudo dari Ms dan mb ke Magnitudo Momen ( $M w$ ) secara matematis dapat dituliskan :

1. Untuk data gempa bumi dengan skala $3,5 \leq$ $m b \leq 6,2$

$M w=(0,85 \times m b)+1,03$

2. Untuk data gempa bumi dengan skala $3,0 \leq M s$ $\leq 6,1$

$M w=0,67 M s+2,07$

3. Untuk data gempa bumi dengan skala $6,2 \leq M s$ $\leq 8,2$

$M w=0,99 M s+0,08$.

(Scordillis, 2006).

Distribusi Gumbel merupakan salah satu teori statistik yang berhubungan dengan nilai-nilai ekstrim.Tujuan dari teori statistik nilai-nilai ekstrim adalah untuk menganalisis hasil pengamatan nilainilai ekstrim, selanjutnya untuk memprediksi nilainilai ekstrim berikutnya.

*Corresponding author: Jurusan Fisika FMIPA UNSRAT, Jl. Kampus Unsrat, Manado, Indonesia 95115; Email address: yustianifrastika@yahoo.co.id

Published by FMIPA UNSRAT (2013) 
Fungsi distribusi kumulatif dari sebaran Gumbel adalah

$$
G(x)=\exp \left(-\exp \left(-\frac{(x-\mu)}{\sigma}\right)\right) ;-\sim<x<\sim . .(4)
$$

dimana $\mu$ merupakan parameterlokasi/nilai rata-rata dan $\sigma$ merupakan parameter skala/simpangan baku.

Penentuan nilai-nilai ekstrim menurut Gilli dan Kellezi (2003), dapat dilakukan dengan dua cara, yaitu:

1. Dengan mengambil nilai-nilai maksimum dalam suatu periode, misalnya periode bulanan atau tahunan; pengamatan atas nilainilai ini dianggap sebagai nilai-nilai ekstrim.

2. Dengan mengambil nilai-nilai yang melampaui suatu nilai threshold; seluruh nilai yang melampaui threshold $u$ (ambang batas $u$ ) dianggap sebagai nilai - nilai ekstrim

Eksplorasi data merupakan salah satu cara untuk pendeteksian awal pendugaan sebaran suatu data. Plot Quantil-Quantil yang sering disebut plot Q$\mathrm{Q}$ atau plot peluang berfungsi untuk memeriksa kesesuaian pola sebaran data terhadap pola sebaran teoritis.Langkah-langkah pemeriksaan pola sebaran data terhadap pola sebaran teoritik dengan plot Q-Q adalah sebagai berikut :

1. Data diurutkan dari yang terkecil sampai yang terbesar.

Misalnya $\mathrm{y}_{(1)}, \mathrm{y}_{(2)}, \ldots, \ldots, \mathrm{y}_{(\mathrm{n})}$.

2. Untuk setiap $\mathrm{y}_{(\mathrm{i})}$, hitung nilai $p_{i}=\frac{(i-0.5)}{n}$; plot $\mathrm{y}_{(\mathrm{i})}$ dengan $p_{i}$ adalah plot kuantil empirik.

3. Untuk setiap $p_{i}$, tentukan nilai $F^{-1}\left(p_{i}\right)=Q\left(p_{i}\right)$ dengan bantuan tabel sebaran normal baku. Plot antara $\left.\mathrm{Q}_{(\mathrm{i}}\right)$ dan $\mathrm{p}_{\mathrm{i}}$ adalah plot kuantil teoritik.

4. Plot antara $\mathrm{y}_{(1)}$ dengan $\mathrm{Q}\left(\mathrm{p}_{\mathrm{i}}\right)$ merupakan plot kuantil-kuantil (Chambers et al., dalam Prang, 2006)

Pemeriksaan pola kesesuaian data sebaran empirik dan sebaran teoritis tertentu dapat menggunakan Uji Kolmogrov-Smirnov (K-S).Uji ini dilakukan dengan menemukan perbedaan terbesar (nilai absolut) antara dua fungsi kumulatif, yaitu sebaran empirik dan teoritis. Misalkan $F_{0}(x)$ adalah suatu fungsi sebaran kumulatif teoritis. Misalkan pula $S_{N}(x)$ adalah sebaran frekuensi kumulatif yang diobsevasi dari suatu sampel acak dengan $N$ observasi dan $\mathrm{x}$ adalah sembarang skor yang mungkin maka $S_{N}(x)=\frac{k}{n}$ dimana $\mathrm{k}$ banyaknya observasi yang $\leq x$. Dengan menetapkan hipotesis $H_{0}: F_{0}(x)=S_{N}(x)$ bahwa sampel suatu observasi berasal dari sebaran tertentu, maka diharapkan untuk setiap harga $x, S_{N}(x)$ harus mendekati $F_{0}(x)$ artinya selisih antara $F_{0}(x)$ dan $S_{N}(x)$ kecil. Uji Kolmogrov-Smirnov memusatkan perhatian pada penyimpangan terbesar (deviasi maksimum) yang dirumuskan:

$D=\operatorname{maks}\left|F_{0}(x)-S_{N}(x)\right|$

Nilai kritis $D$ untuk $\mathrm{n} \leq 35$ tersedia dalam tabel, sedangkan $n>35$ untuk dua arah pada $\alpha=0.05$ dapat menggunakan pembagian $\frac{1.36}{\sqrt{n}}$ dan pada $\alpha=0.01$ dapat menggunakan pembagian $\frac{1.63}{\sqrt{n}}$. Dengan demikian, jika $\mathrm{D} \geq \frac{1.36}{\sqrt{n}}$ pada $\alpha=0.05$ atau $\mathrm{D}$ $\geq \frac{1.63}{\sqrt{n}}$ pada $\alpha=0.01$ maka signifikan, artinya observasi tidak mengikuti distribusi teoritis (Siegel dalam Prang, 2006).

Return Level dalam istilah statistik, atau dalam Geofisika sering disebutkan Return Period, merupakanpengulangan tingkat kejadian gempa bumi, untuk memprediksi keberulangan gempa bumi yang akan terjadi dengan magnitudo tertentu.

Dalam praktek, besaran atau kuantitas yang menjadi perhatian bukan hanya tertuju pada pendugaan parameter itu sendiri, tetapi pada kuantil yang juga disebut sebagai tingkat pengulangan (return level) dari penduga GEV.Jika $F$ adalah sebaran dari nilai maksimum untuk pengamatan pada jangka waktu yang sama, maka tingkat pengulangan akan mengikuti persamaan berikut :

$\hat{R}_{p}^{k}=F^{-1}\left(1-\frac{1}{k}\right)$

dimana $F^{-1}$ adalah fungsi kuantil dari fungsi sebaran $F, k$ adalah jangka waktu dan $p$ adalah periode. Nilai tingkat pengulangan merupakan nilai maksimum yang diharapkan akan dilampaui satu kali dalam jangka waktu $k$ dengan periode $p$ atau dengan kata lain dalam jangka waktu $k$, gempa bumi akan mencapai nilai maksimum $\hat{R}_{p}^{k}$ satu kali (Gilli dan Kellezi , 2003). Setelah dugaan parameter didapat dan disubtitusikan pada persamaan (6), maka diperoleh dugaan tingkat pengembalian :

$\hat{R}_{p}^{k}=\hat{\mu}-\hat{\sigma} \log \left[-\log \left(1-\frac{1}{k}\right)\right]$

(Prang, 2006)

\section{Metode}

Penelitian ini menggunakan data sekunder gempa bumi sejak Januari 1905 sampaiJuni 2013 yang di peroleh dari Katalog gempa bumi ISC (International Seismological Centre). Daerah yang akan diteliti adalah Wilayah Sulawesi yang terletak pada $5^{\circ} \mathrm{LU}$ - $6^{0} \mathrm{LS}$ dan $118^{\circ} \mathrm{BT}$ - $127^{\circ} \mathrm{BT}$ menggunakan metode Distribusi Gumbel.

Langkah-langkah yang dilakukan dalam penelitian ini adalah sebagai berikut :

1. Memilah gempa-gempa utama dengan software ZMAP dan menentukan nilai-nilai ekstrim

2. Melakukan pembagian-pembagian Wilayah yang akan diteliti

3. Melakukan pengujian dan pemeriksaan pola sebaran data dengan menggunakan software SPSS 17 
4. Menentukan nilai dugaan parameter dengan menggunakan software EViews 7

5. Menentukan nilai pengulangan tingkat kejadian (return level) gempa bumi.

\section{Hasil dan Pembahasan}

\subsection{Analisis Gempa Utama dan Nilai Ekstrim}

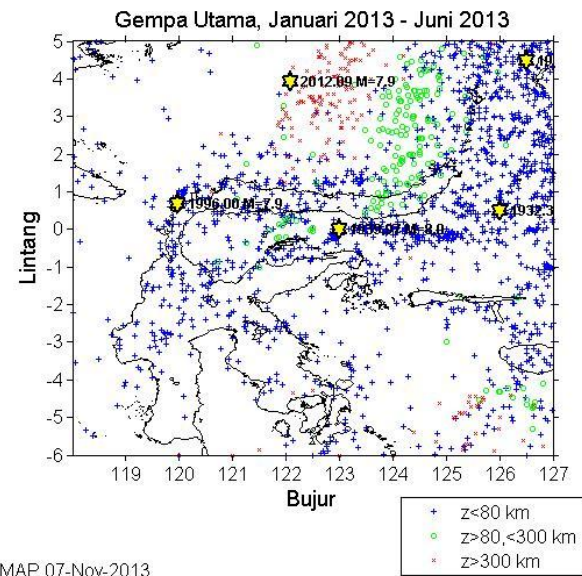

Gambar 2. Kejadian Gempa utama 4-8 Mw di Wilayah Pulau Sulawesi sejak Januari 1905-Juni 2013

Dapat dilihat pada Gambar 2, bahwa Wilayah Sulawesi sangat rawan terhadap kejadian gempa bumi.

Nilai ekstrim gempa bumi, yang diambil dalam penelitian ini adalah $\geq 5,1 \mathrm{Mw}$ karena merupakan kejadian ekstrim yang sering terjadi di Wilayah Sulawesi.

\subsection{Analisis Kejadian Gempa Bumi}

Data gempa bumi yang diperoleh dari katalog gempa ISC (International Seismological Centre) akan dianalisis dengan menggunakan Distribusi Gumbel dengan bantuan software Eviews 7 untuk pendugaan parameter dan SPSS 17 untuk pengujian normalitas data.

Dalam melakukan analisis tidak hanya untuk keperluan pemeriksaan pola sebaran data, tetapi juga untuk pendugaan parameter dan Return Level.Dalam menganalisis Return Level data gempa bumi yang terjadi di Sulawesi sejak Januari 1905Juni 2013 dimaksudkan untuk memberikan gambaran seberapa besar suatu nilai ekstrim gempa bumi, berpeluang akan terjadi dalam jangka waktu tertentu. Nilai Return Level gempa bumi yang diperoleh dapat dijadikan sebagai patokan untuk prediksi terjadinya gempa bumi ekstrim dengan peluang kejadian keberulangan tertentu.

\subsection{Hasil estimasi periode ulang gempa bumi untuk Wilayah Sulawesi:}

Tabel 1. Wilayah Provinsi Sulawesi Utara

\begin{tabular}{|c|c|}
\hline $\mathrm{K}$ (tahun) & Magnitudo (Mw) \\
\hline 2 & 6,2 \\
\hline 3 & 6,3 \\
\hline $4-5$ & 6,4 \\
\hline $6-8$ & 6,5 \\
\hline $9-13$ & 6,6 \\
\hline $14-22$ & 6,7 \\
\hline $23-37$ & 6,8 \\
\hline $38-61$ & 6,9 \\
\hline $62-100$ & 7,0 \\
\hline
\end{tabular}

Tabel 2. Wilayah Provinsi Gorontalo

\begin{tabular}{|c|c|}
\hline K (tahun) & Magnitudo (Mw) \\
\hline 2 & 5,9 \\
\hline 3 & 6,0 \\
\hline $4-5$ & 6,1 \\
\hline $6-7$ & 6,2 \\
\hline $8-12$ & 6,3 \\
\hline $13-18$ & 6,4 \\
\hline $19-29$ & 6,5 \\
\hline $30-46$ & 6,6 \\
\hline $47-74$ & 6,7 \\
\hline $75-100$ & 6,8 \\
\hline
\end{tabular}

Tabel 3. Wilayah Provinsi Sulawesi Selatan

\begin{tabular}{|c|c|}
\hline K (Bulan) & Magnitudo (Mw) \\
\hline $33-68$ & 5,9 \\
\hline $69-148$ & 6,0 \\
\hline $149-318$ & 6,1 \\
\hline $319-686$ & 6,2 \\
\hline
\end{tabular}


Tabel 4. Wilayah Provinsi Sulawesi Tengah

\begin{tabular}{|c|c|}
\hline K (tahun) & Magnitudo $(\mathrm{Mw})$ \\
\hline 2 & 6,1 \\
\hline $3-4$ & 6,2 \\
\hline $5-7$ & 6,3 \\
\hline $8-11$ & 6,4 \\
\hline $12-18$ & 6,5 \\
\hline $19-30$ & 6,6 \\
\hline $31-49$ & 6,7 \\
\hline $50-81$ & 6,8 \\
\hline $82-100$ & 6,9 \\
\hline
\end{tabular}

Tabel 5. Wilayah Provinsi Sulawesi Barat

\begin{tabular}{|c|c|}
\hline K (Bulan) & Magnitudo (Mw) \\
\hline $16-30$ & 5,9 \\
\hline $31-58$ & 6,0 \\
\hline $59-112$ & 6,1 \\
\hline $113-217$ & 6,2 \\
\hline
\end{tabular}

Tabel 6. Wilayah Provinsi Sulawesi Tenggara

\begin{tabular}{|c|c|}
\hline K (tahun) & Magnitudo (Mw) \\
\hline 2 & 5,5 \\
\hline $3-4$ & 5,6 \\
\hline $5-9$ & 5,7 \\
\hline $10-20$ & 5,8 \\
\hline $21-44$ & 5,9 \\
\hline $45-97$ & 6,0 \\
\hline
\end{tabular}

\section{Kesimpulan}

1. Estimasi periode ulang magnitudo gempa bumi menggunakan Distribusi Gumbel dengan tingkat pengulangan kejadian gempabumiuntuk Wilayah Provinsi Sulawesi Utara dalam kurun waktu 62-100 tahun adalah $7 \mathrm{Mw}$, Wilayah Provinsi Gorontalo dalam kurun waktu 75-100 tahun adalah 6,8 Mw, Wilayah Provinsi Sulawesi Tengah dalam kurun waktu 82-100 tahun adalah 6,9 Mw, Wilayah Provinsi Sulawesi Selatan dalam kurun waktu 319-686 bulan adalah 6,2 Mw, Wilayah Provinsi Sulawesi Barat dalam kurun waktu 113-217 bulan adalah 6,2 Mw dan Wilayah Provinsi Sulawesi Tenggara dalam kurun waktu 45-97 tahun adalah 6,0 Mw.

2. Wilayah Provinsi Sulawesi Utara merupakan Wilayah yang paling rawan terhadap kejadian gempa bumi dibandingkan dengan Wilayah lain, karena mempunyai kemungkinan terjadinya gempa bumi dengan magnitudo terbesar.

\section{Daftar Pustaka}

Ibrahim, Gunawan dan Subardjo. 2005. Pengetahuan Seismologi. Badan Meteorologi dan Geofisika, Jakarta.

Ibrahim G.et al. 2010.Kapita Selekta Geofisika. Institut Teknologi, Bandung.

Prang, J.D. 2006. Sebaran Nilai Ekstrim Terampat dalam Fenomena Curah Hujan [tesis]. Sekolah Pascasarjana IPB, Bogor

Pratiwi.2011. Peramalan Gempa Bumi Tektonik untuk Wilayah Sumatera Utara dengan menggunakan metode Distribusi Weibull dan Distribusi Gumbel. [skripsi]. Universitas Sumatera Utara, Medan.

Scordillis, E. 2006. Empirical Global Relations Converting $\mathrm{Ms}$ and $\mathrm{mb}$ to moment magnitude.Journal of Seismology (2006). 10: 225-236. 